\title{
A Study on Distribution and Mode of Origin of Median Nerve and its Relation to the Flexor Retinaculum
}

\author{
Atoofa Jaleel', Ravinder $\mathrm{M}^{2}$ \\ ${ }^{1}$ Assistant Professor, Department of Anatomy, Dr VRK Womens Medical College, Hospital and Research center, Hyderabad, Telangana, India, ${ }^{2} \mathrm{HOD} \&$ \\ Professor, Department of Anatomy, Dr VRK Womens Medical College, Hospital and Research center, Hyderabad, Telangana, India.
}

\section{Abstract}

Introduction: The precise knowledge of level of origin of muscular branches of median nerve are essential in free muscular transfers to restore the mobility of fingers after trauma and to understand the various presentations of nerve entrapment. The anatomical knowledge and variations of recurrent nerve is important to prevent the complications during the release of transverse carpal ligament. Aim \& Objectives: To study the points of origin of muscular branches with respect to IEL and number of branches to muscles of forearm and also learn the mode of origin of recurrent nerve and its relation to the flexor retinaculum. Subjects and Methods: Dissection 40 upper limbs procured from embalmed cadavers of Dr. VRK Women's Medical College, Hospital and Research Centre, Hyderabad, for the study. Results: The mean of point of origin of NPT was $1.21 \mathrm{~cm}$ proximal and $1.20 \mathrm{~cm}$ distal to IEL whereas for NFCR, NPL, NFDS and AIN nerve it was $2.12 \mathrm{~cm}, \mathrm{~cm}, 4.54 \mathrm{~cm}$ and $3.29 \mathrm{~cm}$ distal to IEL respectively. The number of branches to muscles of forearm varied from 1 to 3 . The recurrent nerve was arising from lateral and intermediate branches of median nerve in $39(97.5 \%)$ and 1 specimens (6\%) respectively. Its relationship with flexor retinaculum was extra ligamentous in 33 specimens $(82.5 \%)$ and transligamentous in 7 specimens (17.5\%). It innervated APB, FPB and OP in 19 specimens (47.5\%), only APB, FPB in 16 specimens (45\%) and only APB, OP in 3 specimens (7.5\%). Conclusion: All the muscular branches of median nerve were arising predominantly distal to IEL except nerve to pronator teres. The number of branches varied from 1 to 3 . In majority of the specimens, the recurrent nerve was arising from the lateral terminal branch of median nerve and its relation with flexor retinaculum was extraligamentous.

Keywords: Median nerve; Pronator teres, Anterior interosseous nerve; Recurrent nerve.

Corresponding Author: Dr. Atoofa Jaleel, Assistant Professor, Department of Anatomy, Dr VRK Womens Medical College, Hospital and Research center, Hyderabad, Telangana, India.

Email: jaffarshaik4407@gmail.com

Received: April 2020

Accepted: April 2020

\section{Introduction}

The peripheral nervous system acts as an association between the individual organs and systems with central nervous system. For normal functioning impulses have to be transmitted in the course of the nerves to and from the effector and receptor organs. Consequently the precise comprehension of peripheral innervations of skeletal muscle is vital.

The median nerve is formed in the axilla by the union of the terminal branch of medial and lateral cords of brachial plexus. It then travels a well described path through the arm, across the elbow and through the forearm and reaches the hand by passing deep to the flexor retinaculum. It supplies most of the muscles in the flexor compartment of forearm except flexor carpi ulnaris and ulnar half of flexor digitorum profundus muscles. In the hand it supplies thenar muscles and radial two lumbrical muscles. It is also called as labourer's nerve as it supplies most of the large flexor muscles of the forearm.

Forearm and hand are often injured as they are always in use in exploring and handling tools. Hence median nerve is often caught up in many injuries like fall from height, motor vehicle accidents, collisions, high velocity missiles and other penetrating trauma which generally cause sharp transection of the nerve. Avulsion or traction injuries result in stretching or tearing of the nerve. It can also be injured by electric shock, radiation and thermal injuries.

The supracondylar humeral fractures have been associated with $5-19 \%$ incidence of median nerve injury; there is evidence suggesting a higher incidence of anterior interosseous nerve injury associated with this fracture. ${ }^{[1]}$ The compressive lesions of median nerve commonly occur at two sites - Elbow and Wrist.

The median nerve can be compressed by aponeurotic edge of deep head of pronator teres muscle, ligament of struthers, bicipital aponeurosis and proximal free edge of radial attachment of flexor digitorum superficialis muscle which are collectively called as pronator syndrome.

The anterior interosseous nerve may be affected with median nerve or by itself in any of the causes of pronator syndrome. Anterior interosseous nerve syndrome presents classically as 
an inability to flex the interphalangeal joint of thumb and distal interphalangeal joint of index finger. The most common aetiology of this syndrome is compression by fibrous bands at the deep head of pronator teres muscle or at the tendinous origin of flexor digitorum superficialis. Other causes include trauma, neuralgic amyotrophy (dystrophy), thrombosis of anterior interosseous artery, direct pressure on volar aspect of forearm, and metastatic bronchogenic carcinoma. $^{[2]}$

The anterior interosseous nerve and its branches are vulnerable to injury in open reduction of the fracture of the mid shaft of the radius and in muscle slide procedure. ${ }^{[3]}$

More commonly, median nerve can be compressed when it passes through the fibro-osseous tunnel beneath the flexor retinaculum causing carpal tunnel syndrome.

Non traumatic compression of median nerve is also caused by slowly expanding lesions often vascular in nature like arterial aneurysms, arterio- venous malformations and expanding arterio-venous fistulas for haemodialysis.

The precise knowledge of level of origin of muscular branches of median nerve is required in free muscular transfers to restore mobility of fingers after trauma. ${ }^{[4]}$

Every patient should be considered as possibly having anomalous innervations in the forearm and hand. The knowledge of innervative pattern of median nerve in forearm and hand and their variations are of considerable importance in investigating the lesions of median nerve, to plan adequate treatment and to avoid iatrogenic injuries to the nerve during surgeries there by increasing the perfection of surgical approach.

Hence the present study of muscular distribution of median nerve was undertaken.

\section{Objectives}

1. To study the point of origin of muscular branches of median nerve in the forearm with respect to interepicondylar line.

2. To study the number of branches of median nerve to the muscles of forearm.

3. To study the level of origin of anterior interosseous nerve with respect to interepicondylar line.

4. To learn the mode of origin of recurrent muscular branch in hand.

5. To gain the knowledge of the relations of recurrent nerve to the flexor retinaculum.

\section{Subjects and Methods}

$?$.

\section{Results}

In the present study, 40 upper limbs (22 right and 18 left) from the embalmed cadavers were used to study the myoneural distribution of median nerve.

\section{Nerve to pronator teres:}

In right upper limbs, the nerve to pronator teres was arising from the trunk of median nerve at an average distance of $1.22 \mathrm{~cm} \pm 0.7 \mathrm{~cm}$ (mean $\pm \mathrm{SD}$ ) proximal to the interepicondylar line (range $0.5-3 \mathrm{~cm}$ ) and $0.92 \pm 0.95 \mathrm{~cm}$ distal to the interepicondylar line (range $0-2.5 \mathrm{~cm}$ ) where as in the left upper limbs, it was $1.21 \pm 0.49 \mathrm{~cm}$ proximal to the interepicondylar line (range $0.5-2 \mathrm{~cm}$ ) and $1.46 \pm 1.49 \mathrm{~cm}$ distal to the interepicondylar line (range $0-3.5 \mathrm{~cm}$ ). Out of total 40 specimens, nerve to pronator teres was arising at a mean distance of $1.21 \pm 0.58 \mathrm{~cm}$ proximal to the interepicondylar line (range $0.5-3 \mathrm{~cm}$ ) and $1.2 \pm 1.27 \mathrm{~cm}$ distal to the interepicondylar line $(0-3.5 \mathrm{~cm})$ [Table $1 \& 2$ ].

Table 1: Level of origin of nerve to pronator teres proximal to interepicondylar line

\begin{tabular}{|l|l|l|l|}
\hline Level of origin & Right $(\mathbf{n = 2 2})$ & Left $(\mathbf{n}=\mathbf{1 8})$ & Total $(\mathbf{n}=\mathbf{4 0})$ \\
\hline Range $(\mathrm{cm})$ & $0.5-3$ & $0.5-2$ & $0.5-3$ \\
\hline Mean $(\mathrm{cm})$ & 1.22 & 1.21 & 1.21 \\
\hline $\begin{array}{l}\text { Standard } \\
\text { deviation }(\mathrm{cm})\end{array}$ & 0.7 & 0.49 & 0.58 \\
\hline
\end{tabular}

Table 2: level of origin of nerve to pronator teres distal to intercondylar line

\begin{tabular}{|l|l|l|l|}
\hline Level of origin & Right $(\mathbf{n}=\mathbf{2 2})$ & Left $(\mathbf{n}=\mathbf{1 8})$ & Total $(\mathbf{n}=\mathbf{4 0})$ \\
\hline Range $(\mathrm{cm})$ & $0-2.5$ & $0-3.5$ & $0-3.5$ \\
\hline Mean $(\mathrm{cm})$ & 0.92 & 1.46 & 1.2 \\
\hline $\begin{array}{l}\text { Standard } \\
\text { deviation }(\mathrm{cm})\end{array}$ & 0.95 & 1.49 & 1.27 \\
\hline
\end{tabular}

\section{Nerve to Flexor carpi radialis:}

The mean of point of origin of nerve to flexor carpi radialis was $2.00 \pm 1.10 \mathrm{~cm}$ distal to the interepicondylar line (range 0 $4.5 \mathrm{~cm}$ ) in right upper limbs and $2.15 \pm 1.07 \mathrm{~cm}$ (range $0-4 \mathrm{~cm}$ ) below interepicondylar line in left upper limbs. In total of 40 specimens, the mean of point of origin was $2.18 \pm 1.1 \mathrm{~cm}$ (range $0-4.5 \mathrm{~cm}$ ) below the interepicondylar line [Table 3].

Table 3: Level of origin of nerve to flexor carpi radialis

\begin{tabular}{|l|l|l|l|}
\hline Level of origin & Right $(\mathbf{n = 2 2})$ & Left $(\mathbf{n = 1 8})$ & Total $(\mathbf{n}=\mathbf{4 0})$ \\
\hline Range $(\mathrm{cm})$ & $0-4.5$ & $0-4$ & $0-4.5$ \\
\hline Mean $(\mathrm{cm})$ & 2.00 & 2.15 & 2.18 \\
\hline $\begin{array}{l}\text { Standard } \\
\text { deviation }(\mathrm{cm})\end{array}$ & 1.10 & 1.07 & 1.10 \\
\hline
\end{tabular}

\section{Nerve to Palmaris longus:}

In the right upper limbs, nerve to palmaris longus was arising distal to the interepicondylar line at a mean distance of $2.01 \pm 0.81 \mathrm{~cm}$ (range $0-2.5 \mathrm{~cm}$ ) where as in the left upper limbs, it was $2.19 \pm 1.20 \mathrm{~cm}$ (range $0-3.5 \mathrm{~cm}$ ). Out of 40 specimens, the mean of point of origin of nerve to Palmaris longus was $2.10 \pm 1.10 \mathrm{~cm}$ distal to the interepicondylar line (range $0-4.5 \mathrm{~cm}$ ) [Table 4].

Table 4: level of origin of nerve to palmaris longus

\begin{tabular}{|l|l|l|l|}
\hline Level of origin & Right $(\mathbf{n}=\mathbf{2 1})$ & Left $(\mathbf{n}=\mathbf{1 7})$ & Total $(\mathbf{n}=\mathbf{3 8})$ \\
\hline Range $(\mathrm{cm})$ & 0.2 .5 & $0-3.5$ & $0-4.5$ \\
\hline Mean $(\mathrm{cm})$ & 2.01 & 2.19 & 2.10 \\
\hline $\begin{array}{l}\text { Standard } \\
\text { deviation }(\mathrm{cm})\end{array}$ & 0.81 & 1.20 & 1.10 \\
\hline
\end{tabular}

Out of 40 specimens the palmaris longus muscle was absent in two specimens and in remaining 38 specimens, it was supplied by single branch of median nerve.

\section{Nerve to flexor digitorum superficialis:}

The mean of point of origin of nerve to flexor digitorum superficialis from the interepicondylar line was $4.10 \pm 1.20$ $\mathrm{cm}$ (range $2-7 \mathrm{~cm}$ ) in right upper limbs, and $5.10 \pm 2.70 \mathrm{~cm}$ 
(range $1.5-16.5 \mathrm{~cm}$ ) in left upper limbs. Out of total of 40 cases, it was arising at a mean distance of $4.54 \mathrm{~cm} \pm 2.17 \mathrm{~cm}$ (range 1.5- $16.5 \mathrm{~cm}$ ) distal to the interepicondylar line [Table 5].

$\begin{aligned} & \text { Table 5. Point of origin of nerve to flexor digitorum } \\
& \text { superficialis }\end{aligned}$
\begin{tabular}{|l|l|l|l|}
\hline Level of origin & Right $(\mathbf{n}=\mathbf{2 2})$ & Left $(\mathbf{n}=\mathbf{1 8})$ & Total $(\mathbf{n}=\mathbf{4 0})$ \\
\hline Range $(\mathrm{cm})$ & $2-6$ & $1.5-16.5$ & $1.5-16.5$ \\
\hline Mean $(\mathrm{cm})$ & 4.10 & 5.10 & 4.54 \\
\hline $\begin{array}{l}\text { Standard } \\
\text { deviation }(\mathrm{cm})\end{array}$ & 1.20 & 2.70 & 2.17 \\
\hline
\end{tabular}

\section{Anterior interosseous nerve:}

The mean of point of origin of anterior interosseous nerve distal to the level of interepicondylar line was $3.37 \pm 0.7 \mathrm{~cm}$ (range $1.8-5 \mathrm{~cm}$ ) in right upper limbs and $3.21 \pm 1.05 \mathrm{~cm}$ (right $1.8-6 \mathrm{~cm}$ ) in left upper limbs. Out of total of 40 cases, it was arising at a mean distance of $3.29 \pm 1.00 \mathrm{~cm}$ (range 1.8 to $6 \mathrm{~cm}$ ) distal to the interepicondylar line [Table 6].

\begin{tabular}{l}
\hline Table 6: point of origin of anterior interosseous nerve \\
\begin{tabular}{|l|l|l|l|}
\hline Level of origin & Right $(\mathbf{n = 2 2})$ & Left $(\mathbf{n}=\mathbf{1 8})$ & Total $(\mathbf{n = 4 0})$ \\
\hline Range $(\mathrm{cm})$ & $1.8-5$ & $1.8-6$ & $1.8-6$ \\
\hline Mean $(\mathrm{cm})$ & 3.37 & 3.21 & 3.29 \\
\hline $\begin{array}{l}\text { Standard } \\
\text { deviation }(\mathrm{cm})\end{array}$ & 0.7 & 1.05 & 1.00 \\
\hline
\end{tabular}
\end{tabular}

\section{Nerve to flexor pollicis longus:}

In the right upper limbs, the flexor pollicis longus muscle was innervated from the anterior interosseous nerve by single branch in 20 cases $(90.9 \%)$ and 2 branches in 3 specimens $(9.09 \%)$ where as in the left upper limbs it was by single branch in 13 specimens $(72.2 \%)$ and 2 branches in 2 specimens $(27.7 \%)$. Among total of 40 specimens, 33 specimens $(82.5 \%)$ were innervated by single branch and 7 specimens $(17.5 \%)$ were innervated by 2 branches [Table 7].

\begin{tabular}{|c|c|c|c|c|}
\hline \multicolumn{5}{|c|}{$\begin{array}{l}\text { Table 7: Number of muscular branches of median nerve to the } \\
\text { flexor muscles of forearm }\end{array}$} \\
\hline $\begin{array}{l}\text { Muscular } \\
\text { branch }\end{array}$ & $\begin{array}{l}\text { Number } \\
\text { of } \\
\text { branches }\end{array}$ & $\begin{array}{l}\text { Right } \\
(n=22) \text { No. } \\
(\%)\end{array}$ & $\begin{array}{l}\text { Left } \\
(n=18) \text { No. } \\
(\%)\end{array}$ & $\begin{array}{l}\text { Total } \\
(n=40) \text { No. } \\
(\%)\end{array}$ \\
\hline \multirow[t]{3}{*}{ NPT } & 1 & $14(63.63 \%)$ & $\begin{array}{l}10 \\
(55.55 \%)\end{array}$ & $24(60 \%)$ \\
\hline & 2 & $7(31.81 \%)$ & $6(33.33 \%)$ & $13(32.5 \%)$ \\
\hline & 3 & $1(4.54 \%)$ & $2(11.1 \%)$ & $3(7.5 \%)$ \\
\hline \multirow[t]{2}{*}{ NFCR } & 1 & $22(100 \%)$ & $17(96.4 \%)$ & $39(97.5 \%)$ \\
\hline & 2 & 0 & $1(3.8 \%)$ & $1(2.5 \%)$ \\
\hline NPL & 1 & $21(100 \%)$ & $18(100 \%)$ & $39(100 \%)$ \\
\hline \multirow[t]{3}{*}{ NFDS } & 1 & $20(90.90 \%)$ & $\begin{array}{l}13 \\
(72.22 \%)\end{array}$ & $33(82.5 \%)$ \\
\hline & 2 & $1(4.54 \%)$ & $5(27.7 \%)$ & $6(15 \%)$ \\
\hline & 3 & $1(4.54 \%)$ & $2(11.1 \%)$ & $3(7.5 \%)$ \\
\hline \multirow[t]{2}{*}{ NFPL } & 1 & $20(90.90 \%)$ & $13(72.2 \%)$ & $33(82.5 \%)$ \\
\hline & 2 & $2(9.09 \%)$ & $5(27.7 \%)$ & $7(17.5 \%)$ \\
\hline \multirow[t]{3}{*}{ NFDP } & 1 & $15(68.18 \%)$ & $16(88.8 \%)$ & $31(77.5 \%)$ \\
\hline & 2 & $5(22.7 \%)$ & $1(5.55 \%)$ & $6(15 \%)$ \\
\hline & 3 & $1(4.54 \%)$ & $1(5.55 \%)$ & $2(5 \%)$ \\
\hline
\end{tabular}

\section{Nerve to flexor digitorum profundus:}

In right upper limbs, the number of branches from the anterior interosseous nerve to flexor digitorum profundus muscle was single in 17 specimens $(70.8 \%), 2$ in 6 specimens $(25 \%)$, and 3 in 1 specimen $(4.2 \%)$ where as in left upper limbs, it was single in 23 specimens (88.5\%), 2 in
2 specimens $(7.7 \%)$ and 3 in one specimen $(3.8 \%)$. In one specimen nerve to flexor digitorum profundus was arising directly from the trunk of median nerve.

\section{Recurrent branch of median nerve:}

On the right side, the mode of origin of recurrent nerve was from lateral branch of median nerve in 20 specimens $(90.90 \%)$ and intermediate branch in 2 specimens $(9.09 \%)$ where as in left upper limbs, it was from lateral branch in 17 specimens $(94.44 \%)$ and from intermediate branch in one specimen $(5.55 \%)$. Out of total 40 specimens, it was arising from lateral branch in 37 specimens $(92.5 \%)$, and from intermediate branch in 3 specimens $(7.5 \%)$. In none of the specimens, recurrent nerve showed ulnar origin. [Table 8]

Table 8: Mode of Origin of Recurrent Nerve

\begin{tabular}{|l|l|l|l|}
\hline Mode of origin & $\begin{array}{l}\text { Right } \\
(\mathbf{n = 2 2})\end{array}$ & Left $(\mathbf{n = 1 8})$ & $\begin{array}{l}\text { Total } \\
(\mathbf{n = 4 0})\end{array}$ \\
\hline Lateral branch & $20(90.90 \%)$ & $17(94.44 \%)$ & $37(92.5 \%)$ \\
\hline Intermediate branch & $2(9.09 \%)$ & $1(5.55 \%)$ & $3(7.5 \%)$ \\
\hline
\end{tabular}

The relation of recurrent nerve to flexor retinaculum was extraligamentous in all the right upper limbs, where as it was extraligamentous in 14 specimens $(77.7 \%)$ and transligamentous in 4 specimens $(22.22 \%)$ in left upper limbs. Out of total of 40 cases, 36 specimens (90\%) showed extraligamentous course and 6 specimens (10\%) showed transligamentous course. [Table 9]

Table 9: Relation of recurrent nerve to flexor retinaculum
\begin{tabular}{|l|l|l|l|}
\hline $\begin{array}{l}\text { Relation of } \\
\text { recurrent nerve to } \\
\text { flexor retinaculum }\end{array}$ & $\begin{array}{l}\text { Right } \\
(\mathbf{n = 2 2})\end{array}$ & Left $(\mathbf{n = 1 8})$ & $\begin{array}{l}\text { Total } \\
(\mathbf{n = 4 0})\end{array}$ \\
\hline Extraligamentous & $22(100 \%)$ & $14(77.7 \%)$ & $36(90 \%)$ \\
\hline Transligamentous & 0 & $4(22.22 \%)$ & $4(10 \%)$ \\
\hline
\end{tabular}

Among 22 right upper limbs, the recurrent nerve innervated abductor pollicis brevis, flexor pollicis brevis and opponens pollicis in 10 specimens $(45.45 \%)$, only abductor pollicis brevis and flexor pollicis brevis in 12 specimens $(54.54 \%)$. Where as in left upper limbs, it innervated abductor pollicis brevis, flexor pollicis brevis, opponens pollicis in 9 specimens $(50 \%)$, only abductor pollicis, flexor pollicis brevis in 6 specimens $(33.33 \%)$ and only abductor pollicis brevis opponens pollicis in 3 specimens $(16.66 \%)$. Out of total of 40 cases, recurrent nerve innervated abductor pollicis brevis, flexor pollicis brevis and opponens pollicis in 20 specimens $(50 \%)$, only abductor pollicis brevis and flexor pollicis brevis in 16 specimens (40\%) and only abductor pollicis brevis, opponens pollicis in 4 specimens $(10 \%)$ [Table 10].

Table 10: Thenar muscles innervated by recurrent nerve

\begin{tabular}{|l|l|l|l|}
\hline $\begin{array}{l}\text { Thenar muscles } \\
\text { innervated by } \\
\text { recurrent nerve }\end{array}$ & $\begin{array}{l}\text { Right } \\
(\mathbf{n = 2 2})\end{array}$ & $\begin{array}{l}\text { Left } \\
(\mathbf{n = 1 8})\end{array}$ & $\begin{array}{l}\text { Total } \\
(\mathbf{n = 4 0 )}\end{array}$ \\
\hline APB, FPB, OP & $10(45.8 \%)$ & $9(50 \%)$ & $19(47.5 \%)$ \\
\hline APB, FPB & $12(54.2 \%)$ & $6(33.33 \%)$ & $18(45 \%)$ \\
\hline APB, OP & 0 & $3(16.66 \%)$ & $3(7.5 \%)$ \\
\hline
\end{tabular}

In one specimen accessory thenar nerve was arising from proper digital nerve to the radial side of the thumb and innervated the flexor pollicis brevis. 
The proper digital nerve to radial side of index finger supplied first lumbrical in all the 40 specimens (100\%).

The lateral common digital nerve innervated the $2^{\text {nd }}$ lumbrical in all the 40 specimens $(100 \%)$.

The medial common digital nerve innervated the third lumbrical in 6 specimens (15\%). Out of which 2 specimens $(9.09 \%)$ belong to right side and 4 specimens $(22.22 \%)$ belong to left side [Table 12].

Table 12: Lumbricals innervated by median nerve
\begin{tabular}{|l|l|l|l|}
\hline $\begin{array}{l}\text { Lumbricals } \\
\text { innervated by } \\
\text { median nerve }\end{array}$ & $\begin{array}{l}\text { Right } \\
(\mathbf{n = 2 2})\end{array}$ & Left $(\mathbf{n = 1 8})$ & $\begin{array}{l}\text { Total } \\
(\mathbf{n = 4 0})\end{array}$ \\
\hline LU1 by PDNRI & $22(100 \%)$ & $18(100 \%)$ & $40(100 \%)$ \\
\hline LU2 BY LCDN & $22(100 \%)$ & $18(100 \%)$ & $40(100 \%)$ \\
\hline LU3 BY MCDN & $2(9.09 \%)$ & $4(22.22 \%)$ & $6(15 \%)$ \\
\hline
\end{tabular}

\section{Discussion}

The importance of muscular branches of the median nerve is worth, as it innervates most of the muscles of flexor compartment of forearm, thenar muscles and lumbricals cumulatively responsible for the efficiency of the thumb and multiple activities of the hand.

\section{Nerve to pronator teres:}

In the present study, the level of origin of nerve to pronator teres varied between $3 \mathrm{~cm}$ proximal to interepicondylar line and $2.5 \mathrm{~cm}$ distal to interepicondylar line in right upper limbs whereas in left upper limbs it was $2 \mathrm{~cm}$ proximal to interepicondylar line and $3.5 \mathrm{~cm}$ distal to interepicondylar line. In study made by Alves N., the level of origin of nerve to pronator teres was between $4 \mathrm{~cm}$ proximal to interepicondylar line and $1 \mathrm{~cm}$ distal to inter epicondylar line in right upper limbs whereas in left upper limbs, it was $4.9 \mathrm{~cm}$ proximal to interepicondylar line and $1.6 \mathrm{~cm}$ distal to interepicondylar line. ${ }^{[5]}$

In study made by Sunderland, the level of origin of nerve to pronator teres varied between $7 \mathrm{~cm}$ proximal to medial epicondyle and $2.3 \mathrm{~cm}$ distal to the medial epicondyle. In the present study of 40 specimens, the mean of point of origin of nerve to pronator teres was $1.2 \mathrm{~cm}$ below the interepicondylar line whereas in a study made by Canovas F., it was $2.4 \mathrm{~cm}$ below the interepicondylar line. ${ }^{[4]}$

In the present study, the number of muscular branches to pronator teres muscle was 1 to 3 . Out of 40 specimens, the pronator teres muscle was innervated by single branch in 24 specimens $60 \%$ ), 2 branches in 13 specimens (32.5\%) and 3 branches in 3 specimens $(7.5 \%)$. This correlates with study made by Alves N. who observed 1 to 3 branches from the median nerve innervating pronator teres muscle. ${ }^{[5]}$

\section{Nerve to flexor carpi radialis:}

In the present study, out of total 40 specimens, the nerve to flexor carpi radialis was arising from the trunk of median nerve at a mean distance of $2.18 \mathrm{~cm}$ below the interepicondylar line. This correlates with study made by Canovas, in which it was arising from mean distance of $2.5 \mathrm{~cm}$ below the interepicondylar line.

In the present study, the level of origin of nerve to flexor carpi radialis varied between $0 \mathrm{~cm}$ (at the level of interepicondylar line) and $4.5 \mathrm{~cm}$ distal to the interepicondylar line, where as in the study made by Sunderland, it was $1.5 \mathrm{~cm}$ proximal to interepicondylar line and $5 \mathrm{~cm}$ distal to the interepicondylar line. ${ }^{[4]}$

In the present study, out of 40 specimens, the flexor carpi radialis muscle was innervated from median nerve by single branch in 39 specimens $(97.5 \%)$ and by 2 branches in 1 specimen $(2.5 \%)$ whereas Sunderland observed, flexor carpiradialis muscle to be innervated by single branch in 18 specimens $(90 \%)$ and by 2 branches in 2 specimens $(10 \%)$ out of twenty specimens. ${ }^{[4]}$

\section{Nerve to Palmaris longus:}

In the present study, the mean of point of origin of nerve to Palmaris longus was $2.10 \mathrm{~cm}$ distal to interepicondylar line which correlates with study made by Canovas F., in which it was $2.5 \mathrm{~cm}$ distal to the interepicondylar line. ${ }^{[4]}$ According to Moore, palmaris longus muscle is absent on one or both sides in $14 \%$ of people. ${ }^{[6]}$

\section{Nerve to flexor digitorum superficialis:}

In the present work, the average of level of origin of nerve to flexor digitorum superficialis was $4.54 \mathrm{~cm}$ distal to interepicondylar line whereas Canovas F., has reported it as $3.5 \mathrm{~cm}$ distal to interepicondylar line. ${ }^{[4]}$

In the present study, flexor digitorum superficialis was innervated by single branch in 33 specimens $(82.5 \%)$, by 2 branches in 6 specimens $(15 \%)$ and by 3 branches in 3 specimens $(7.5 \%)$.

\section{Anterior interosseous nerve:}

In the present study, the point of origin of anterior interosseous nerve was between $1.8 \mathrm{~cm}$ and $6 \mathrm{~cm}$ distal to interepicondylar line. This correlates with study made by Canovas $(2 \mathrm{~cm}-6.5 \mathrm{~cm})$ and Sunderland $(2.3 \mathrm{~cm}-8 \mathrm{~cm})$. The average of point of origin of anterior interosseous nerve in the present study was $3.29 \mathrm{~cm}$ which correlates with observation reported by Canovas $(4.3 \mathrm{~cm})$. However it is lower than the values reported by Sunderland $4(5.1 \mathrm{~cm})$.

\section{Nerve to flexor pollicis longus:}

In the present study the flexor pollicis longus muscle was supplied by single branch from anterior interosseous nerve in 33 specimens $(82.5 \%)$ and by 2 branches in 7 specimens $(17.5 \%)$ where as in study made by Canovas, it was innervated by 1-4 small branches from anterior interosseous nerve. Sunderland had observed 2-6 branches from anterior interosseous nerve innervating the flexor pollicis longus muscle. ${ }^{[4]}$

\section{Nerve to flexor digitorum profundus:}

In the present study, the flexor digitorum profundus was innervated by 1 to 3 branches from the anterior interosseous nerve. In 40 specimens $(77.5 \%)$ it was receiving single branch, in 6 specimens (15\%) two branches and 2 specimens $(5 \%)$ three branches from anterior interosseous nerve. This correlates with study of Canovas, who observed 1-4 
branches from anterior interosseous nerve innervating the flexor digitorum profundus muscle. However it is lower than observations made by Sunderland who reported 2-6 branches in 17 out of 20 cases.

In the present study, the flexor digitorum profundus muscle in one specimen was innervated by a branch directly from the trunk of median nerve which was the only nerve supply to this muscle. Sunderland has reported supplementary branches directly from median nerve innervating the flexor digitorum profundus muscle in $10 \%$ of the specimens. ${ }^{[4]}$

In all the 40 specimens, the pronator quadratus muscle was supplied by anterior interosseous nerve which passed deep to the muscle to supply it.

\section{Recurrent nerve:}

In the present work, the recurrent nerve was arising from lateral branch of median nerve in 37 specimens $(92.5 \%)$ and from intermediate branch in 3 specimens $(7.5 \%)$ but none of the specimens showed medial origin. Sacks JM., in his study, had noted lateral origin of recurrent nerve in all the specimens $(100 \%) .{ }^{[7]}$ Where as Olave E., has reported $83.3 \%$ specimens with lateral origin and $1.7 \%$ specimens with intermediate origin. ${ }^{[8]}$

In the present study, the relation of recurrent nerve to flexor retinaculum was extraligamentous in $90 \%$ of specimens which correlates with observations of Sacks, ${ }^{[15]}(92 \%)$ and Sennayake (88\%). ${ }^{[9]}$ It was transligamentous in $10 \%$ specimens in the present study which correlates with observations of Sacks (8\%). ${ }^{[15]}$ However it is higher when compared to observations of Sennayake who had not observed any transligamentous course of recurrent nerve in his study. ${ }^{[9]}$

In the present study of 40 cases, the recurrent nerve was innervating abductor pollicis brevis, flexor pollicis brevis and opponens pollicis in $47.5 \%$ of specimens which correlates with observations of Olave E., $(50 \%),{ }^{[10]}$ Ajmani $(54 \%),{ }^{[11]}$ and Mumford $(45 \%),{ }^{[10]}$ but it is lower than the values reported by Desoja $(63.3 \%) .{ }^{[10]}$ In the present study, it was innervating only abductor pollicis brevis and flexor pollicis brevis in $45 \%$ of specimens which is higher than observations of Ajmani (7\%). ${ }^{[1]}$ It was innervating only abductor pollicis brevis and opponens pollicis in $7.5 \%$ of specimens in the present study. Ajmani reported $35 \%$ of specimens and Mumford 30\% of specimens showing only abductor pollicis brevis and opponens pollicis muscles innervated by recurrent nerve which are higher than the values observed in our study. ${ }^{[12]}$

In the present study, accessory thenar nerve from proper digital nerve to thumb was innervating flexor pollicis brevis in one specimen $(2.5 \%)$. Which was low when compared to previous studies.

In the present study of 40 specimens, proximal digital nerve to radial side of index finger was innervating first lumbrical muscle in all specimens which correlates with observations of Ajmani. ${ }^{[12]}$

In the present work, lateral common digital nerve was innervating second lumbrical in all the 40 specimens where as Ajmani has observed lateral common digital nerve innervating $92 \%$ of the specimens. ${ }^{[12]}$

In the present study, medial common digital nerve innervated third lumbrical in 6 specimens (15\%) which is lower than the values reported by Ajmani (30.8\%). ${ }^{[12]}$

\section{Conclusion}

In greater number of the specimens, the nerve to the pronator teres was arising from the median nerve proximal to the interepicondylar line. In considerable number of specimens, the pronator teres was innervated by multiple branches ( 1 to 3 ) from the median nerve. In a large number of the specimens, the nerve to flexor carpi radialis and nerve to Palmaris longus were arising distal to the interepicondylar line. The flexor carpiradialis and palmaris longus predominantly received single branch from the median nerve. In all the specimens, the nerve to flexor digitorum superficialis and anterior interosseous nerve were arising distal to the interepicondylar line. In majority of the specimens, the flexor digitorum superficialis received single branch from the median nerve and flexor pollicis longus and flexor digitorum profundus received single branch from the anterior interosseous nerve respectively. In all the specimens, the anterior interosseous nerve passed deep to pronator quadratus muscle to innervate it. Except few specimens, the recurrent nerve was arising from the lateral branch of the median nerve and its course was extraligamentous in relation to flexor retinaculum. Transligamentous variant was comparatively rare.

\section{Acknowledgment}

The author Thankful to Department of Anatomy, Dr VRK WOMEN'S Medical College \& Hospital for providing all the facilities to carry out this work.

\section{References}

1. Tetro AM, Pichora DR. High median nerve entrapments an obscure cause of upper extremity pain. J Anat 1996;23:445-449.

2. Ong ETL, Vaikunthan R. Anterior interosseous nerve syndrome. Sing Med J 1988;29:472-475.

3. Spinner M. The anterior interosseous nerve syndrome : With special attention to it's variations. J Bone Joint Surg Am 1970;52:84-94

4. Canovas F, Moulleron PH, Bonnel F. Biometry of the muscular branches of the median nerve to the forearm. Clin Anat 1998;11:239-245.

5. Alves N, Candido PL, Frazao R. Innervation of the pronator teres muscles. Int J Morphol 2004;22(3):237-240.

6. Moore AL, Dalley II AF. Clinically oriented anatomy. 4th Edn. Philadelphia : Lippincott Williams and Wilkins; 1999 .p.737.

7. Sacks JM, Kuo YR, Mclean K, Wollstein R, Lee WPA. Anatomical relationship among the median nerve thenar branch, superficial palmar arch and transverse carpal ligament. Plast Reconst Surg 2007;120(3):713-718.

8. Olave E, Prates JC, Gabriell C, Pardi P. Morphometric studies of the muscular branch of the median nerve. J Anat 1996;23:445-449.

9. Senanayake KJ, Salgado S, Fernando R. Course pattern of the muscular branch of the median nerve in Srilankans hand. Int J Morphol 2009;27(4): 1059-1061.

10. Olave E, Prates JC, Sol MD, Sarmento A, Gabriell C. Distribution pattern of the muscular branch of the median nerve in the thenar region. J Anat 1995; 441-446.

11. Ajmani ML. Variations in the motor nerve supply of the thenar and hypothenar muscles of the hand. J Anat 1996;189:145-150.

12. Ajmani ML. Morphological variations of lumbrical muscles in the human hand with some observations on its nerve supply. Med J Iran Hosp 2001;17: 20-24. 
Copyright: () the author(s), 2020. It is an open-access article distributed under the terms of the Creative Commons Attribution License (CC BY 4.0), which permits authors to retain ownership of the copyright for their content, and allow anyone to download, reuse, reprint, modify, distribute and/or copy the content as long as the original authors and source are cited.

How to cite this article: Jaleel A, Ravinder M. A Study on Distribution and Mode of Origin of Median Nerve and its Relation to the Flexor Retinaculum. Acad. Anat. Int. 2020;6(1):20-25.

DOI: dx.doi.org/10.21276/aanat.2020.6.1.5

Source of Support: Nil, Conflict of Interest: None declared. 